\title{
Dependence of Health Saving Function of Special Purpose Footwear on Its Consumer Properties
}

\author{
Lilia Yu. MAKHOTKINA \\ Ph.D. (in Technical Sciences) \\ Professor \\ Head of the Apparel and Footwear Design Department \\ Kazan National Research Technological University \\ Institute of Textile Industry Technologies, Fashion and Design \\ 68, Karl Marx Str., Kazan, 420015, Russia \\ lili_makh@mail.ru \\ Lyudmila L. NIKITINA \\ Ph.D. (in Pedagogical Sciences) \\ Associate Professor \\ Apparel and Footwear Design Department \\ Kazan National Research Technological University \\ Institute of Textile Industry Technologies, Fashion and Design \\ 68, Karl Marx Str., Kazan, 420015, Russia \\ naik@bk.ru

\section{Rinat M. YARULLIN} \\ Senior Laboratory Assistant \\ Department of Textile Industry Materials and Technologies \\ Kazan National Research Technological University \\ Institute of Textile Industry Technologies, Fashion and Design \\ 68, Karl Marx Str., Kazan, 420015, Russia \\ yarr90@yandex.ru
}

Natalia V. TIKHONOVA

Ph.D. (in Pedagogical Sciences)

Professor

Apparel and Footwear Design Department

Kazan National Research Technological University

Institute of Textile Industry Technologies, Fashion and Design

68, Karl Marx Str., Kazan, 420015, Russia

nata.tikhonova.81@mail.ru

\section{Guzel I. GARIPOVA}

Ph.D. (in Technical Sciences)

Associate Professor

Apparel and Footwear Design Department

Kazan National Research Technological University

Institute of Textile Industry Technologies, Fashion and Design

68, Karl Marx Str., Kazan, 420015, Russia

fusion@mail.ru

\section{Lilia R. HANNANOVA-FAKHRUTDINOVA}

Ph.D. (in Pedagogical Sciences)

Associate Professor 


\author{
Department of Designing Clothes and Shoes \\ Kazan National Research Technological University \\ Institute of Textile Industry Technologies, Fashion and Design \\ 68, Karl Marx Str., Kazan, 420015, Russia \\ Lilyakhannanova@mail.ru
}

\begin{abstract}
Recently, there has been a tendency to consider the health of workers as a significant human resource of the organization. For the management of enterprises, it becomes economically profitable to develop and apply various measures aimed at preserving and preserving the health of workers. Special-purpose footwear as a means of individual protection is increasingly considered from the standpoint of health preservation, since the employee is in special footwear during the entire working time. In this context, special-purpose footwear should not only prevent or reduce the impact of harmful and hazardous production factors, but itself should not be a source of harmful or hazardous production factors that negatively affect the health of the wearer. In the process of performing the work, we found that the health-preserving function of special-purpose footwear depends on the protective, ergonomic and safety properties. Safety shoes should not have a negative effect on the structure of the foot, cause diseases of the human musculoskeletal system due to the irrational shape of the shoe, cause eczematic and allergic reactions due to the use of materials that are not harmless to the human body, especially on the inner parts of the shoe. and safety properties, primarily biological, of special-purpose footwear in the process of wearing lead to a change in the health-preserving function.
\end{abstract}

Keywords: footwear for special purposes; health preservation function; consumer properties; choice of materials; rational design.

\title{
Introduction
}

The health of workers is a significant human resource for the modern economy in general and for any organization in particular. For organizations, it becomes economically profitable to develop and apply various measures aimed at preserving and preserving the health of workers. Therefore, every day, various health-preserving technologies, which are a system of measures to preserve and strengthen human health, are becoming more and more relevant. One of these measures is the use of certified personal protective equipment by employees at work with harmful and (or) hazardous working conditions, which include special-purpose footwear.

In this context, footwear should not only prevent or reduce the impact of harmful and hazardous production factors, but itself should not be a source of harmful or dangerous factors that negatively affect the health of the wearer. Accordingly, health-preserving becomes the main function of special-purpose footwear. This function is complex and depends on the performance of the shoes during operation of all the protective and physiological and hygienic functions assigned to them in the design. The ability of shoes to perform certain functions is expressed in terms of its consumer properties.

The disclosure of the health-preserving function of special-purpose footwear is possible through consideration of its consumer properties and establishing the dependence of the health-preserving function on its consumer properties. The concept of "addiction" is disclosed in mathematics. It sets the correspondence between the change in the function and the change in the value of the variables. In our case, consumer properties are used as variables. Establishment of dependence is possible on the basis of a theoretical analysis of the available information on the problem of health preservation and provision of consumer properties of footwear in various sources and the results obtained during the experiment. 


\section{Literary Review}

During the study, the works of mainly domestic authors were studied, since there are few publications in a foreign language in the field under study. In the works of Lyubich, Zurabyan, Kedrov and others, the theoretical foundations of studying the properties of shoes are revealed. The most comprehensive properties of footwear were considered by Lubich (1969). His work was published in 1969, later researchers studied only certain properties of shoes or materials used in its production, as well as their classification. Research by Zurabyan, Krasnova, Bernstein (1988) is aimed at studying the properties of materials used for the production of footwear. Zayonchkovsky and Krasnov (1977) investigated the antistatic properties of polymeric materials.

The work of Kedrov (1979) is devoted to issues related to the heat-shielding properties of footwear, Reshetneva and Kalita (1978) to study and improve the waterproof properties of sports shoes. In the works of Magomedov (2007), Akimova (2005), Ivanov and Glazer (1982), and Makhotkina, Nikitina, and Gavrilova (2017) considered various classifications of consumer properties of footwear. In this study, we rely on the classification of consumer properties of footwear presented in the work of Makhotkina, Nikitina, Gavrilova.

Health preservation is understood as a purposefully carried out complex of scientifically grounded psychological, therapeutic, preventive and other measures aimed at preserving and strengthening human health (Yarullin, Nikitina, Makhotkina, Tikhonova, 2019). Research in the field of technologies of leather, fur, footwear and leather goods, devoted to the problem of health preservation in general and We have not found a study of the health-preserving function of footwear and the methodology for designing health-preserving footwear in particular. However, there are works, the research results of which can be used in disclosing various aspects of research and development of health-saving shoes. There are a number of works considering the provision of the health-preserving function of footwear from the standpoint of interaction with the support (Alexandrov, Zhukovskaya, 2014; Alexandrov, Zhukovskaya, 2019).

Research by Polukhina (2004) is devoted to the regulation of the biological properties of materials. The paper considers the possibility of improving the biological safety of materials from colonies of microorganisms of the genus Trichophyton, molds causing fungal diseases, due to the modification of the surface of materials by physical, chemical and physicochemical methods. The biological safety of materials was assessed by comparing the number of colonies of microorganisms before and after treatments. The author of the study considered the biological safety of medical materials.

Speaking about the biological safety of special-purpose footwear during operation, it is necessary to study the surface of the materials of the in-footwear space for the presence of colonies of microorganisms that cause fungal diseases of the feet at various stages of wearing. If necessary, it is possible to use the proposed methods of surface treatment of materials in the work of Polukhina to ensure the necessary indicators of biological safety. In this case, the processed materials must be examined for their behavior during prolonged wear in order to answer the following questions. Are the acquired antifungal properties long-term? Does the antifungal treatment affect other material properties? Is the wear resistance of the material deteriorating?

The results of work on the design of orthopedic footwear Kostyukhova (1999), Kiselev (2004), Maksimova (2003), Savoskin (2016) and footwear of increased comfort Kiseleva (2008). The paper by Savoskin (2016), in which the author develops various technological equipment, separates units for the construction of the top and bottom of the shoe to improve the comfort of the shoe construction and work in the field of medicine Belgorodsky (2001) and Nikolaeva (1999), establishing the relationship of foot pathologies with the design features of shoes, can be used in the design process of footwear to ensure its health-preserving function in terms of preventing foot diseases, as well as treating various defects of the musculoskeletal system in the early stages. 
The authors considered and proposed various materials and design solutions for the manufacture of orthopedic shoes. However, due to the significant difference in the assigned functions and wearing conditions between orthopedic footwear and special-purpose footwear, the possibility of using the proposed materials and design developments in special footwear should be studied. In this regard, it is advisable to study the possibility of using various orthopedic insoles in special-purpose shoes and select the most optimal types of them, consider them during operation, how they change with prolonged and active use, do they cause injuries in sockets without foot pathologies, etc.

\section{Methods and Materials}

To establish the dependence of the health-preserving function on its consumer properties, at the initial stage, it is necessary to determine the properties of shoes that affect the health of the wearer, and then it is advisable to conduct an experiment to confirm the revealed dependence.

By consumer properties we will mean a group of properties that determines the objective features of a consumer product, manifested in the process of operation (consumption), and ensures the satisfaction of specific human needs. These include protective properties that determine the ability of a product to satisfy a person's need for protection from adverse environmental influences, ergonomic - the need for convenience and comfort during its operation, aesthetic - a person's needs for beauty, a safety property - a person's need for safety of life and health, reliability - a person's need to save money.

Protective properties protect workers' feet from negative environmental influences such as falling heavy objects, punctures, cuts, electric shocks, etc. Inadequacy of the protective properties of shoes mainly leads to production injuries: bruises, sprains, dislocations, fractures, burns, etc. All indicators of protective properties are clearly spelled out and regulated in regulatory documents. Thus, special-purpose footwear, the indicators of the protective properties of which correspond to regulatory documents, prevent foot injuries associated with external influences, as well as prevent the occurrence of occupational foot diseases. Accordingly, the health-preserving function is manifested in the ability of safety shoes to protect the wearer from possible injuries resulting from external exposure, and to prevent the occurrence of occupational diseases due to external influences (everyday presence of a person in conditions of increased vibration can lead to diseases of the spine, etc.). Compliance of the protective properties of safety footwear with the operating conditions ensures its health-preserving function largely due to the rational selection of the materials used for the details of the top and bottom of the shoe.

Ergonomic properties are designed to provide comfort and convenience while wearing, i.e., correspond to the anthropometric parameters of the foot, power and energy capabilities of a person, as well as the intensity of wearing. Shoes with high ergonomic properties ensure the formation of correct posture and a rational and comfortable posture when walking and running. Such ergonomic properties of footwear for special purposes, such as weight, flexibility and hygienic properties, have a significant impact on the fatigue of workers, the development of occupational diseases: static deformities of the foot - longitudinal flat feet, fungal diseases of the skin of the feet, excessive sweating of the feet - hyperhidrosis. Reducing fatigue mainly depends on the even distribution of body weight on the plantar surface of the foot with a static nature of work and the flexibility of the shoe in the case of a dynamic one. The uniform distribution of human body weight is ensured by the correspondence of the inner shape of the shoe to the shape of the plantar surface of the foot.

Prolonged wearing of improperly selected shoes that restrict the foot leads to circulatory disorders, the consequences of which are arthritis and arthrosis of the joints of the feet, vascular diseases, flat feet. Inconsistency of ergonomic properties leads to diseases of the feet, which are characterized by the following symptoms: quickly onset leg fatigue, pain in the heels, burning sensation, numbness, pain and cramps in the muscles of the foot, calluses on the feet, poor mobility of the joints of the foot. Pain in the feet is a springboard for the further development of diseases in the hip and knee joints, in the back, and also cause general weakness, migraines, and irritability. 
Special footwear with high ergonomic properties contributes to the formation of correct posture, provides a rational and comfortable posture when walking and running, and the prevention of static foot deformities, occupational diseases and the occurrence of fungal diseases and contribute to the treatment of hyperhidrosis. Health-preserving footwear for special purposes should ensure the performance of the socks throughout the entire working time, which is largely determined by the corresponding ergonomic properties of the footwear (weight, stiffness, microclimate of the in-shoe space), which help to reduce the fatigue of the wearer.

These indicators depend on both the properties of the materials and the design solutions of the shoe. At the stage of choosing the inner shape of the shoe, its ergonomic properties are laid, i.e., the convenience of the shoe, which depends on the size and shape of the shoe on which it is made. Shoes will be comfortable if there is no squeezing of the top of the foot in the area of the toes, in the beam part and in the area of the ankles during wearing, as well as if the surface of the insole is close to or repeats the surface of the plantar surface of the foot, forming a so-called bed.

The safety property of special-purpose footwear is determined by its ability to ensure the harmlessness of its consumption for human health and life (Makhotkina, Tikhonova, Zhukovskaya, Garipova, Kovalenko, Fatkhullina, Khristoliubova, 2020). The biological hazard of shoes is associated with the development of microorganisms on the inner surface of products that contribute to the appearance of fungal diseases, chemical hazard - with the release of substances harmful to the human body into the intra-shoe space and their further migration to the skin of the foot, mechanical hazard - with the presence of elements in the structure that can cause physical injury (for example, a protective metal toe cap, when exposed to a load of more than 200 Joules, can bend towards the base of the toes, which can lead to injuries and serious injuries to the foot).

The discrepancy between the safety properties of footwear mainly leads to the occurrence of occupational diseases: eczema with insufficient chemical safety of footwear, foot fungus (mycosis) with insufficient biological safety. Mechanical safety prevents injury from the shoe parts themselves. For example, when a metal toe cap is deformed, there is a possibility of injury to the toes, up to and including a fracture. Chemical and biological safety of materials is ensured by conducting sanitary and epidemiological control, the result of which is the availability of a sanitary and epidemiological conclusion on the materials used (Weir, Hamill, Willwacher, Trudeau, Wyatt, 2020).

The most common disease is foot fungus (mycosis), the causative agents of which are microorganisms of the Trichophyton genus, as well as molds. The main conditions for the occurrence of foot infection with shoes are: wearing tight shoes (when the feet are squeezed, cracks and bedsores are formed, in which infection easily develops); hyperhidrosis (excessive sweating of the legs); high humidity inside the shoe space. The disease is transmitted from the materials used for the inner parts of the upper and lower parts of the shoe (Serweta, Olejniczak, Lason-Rydel, Matusiak, 2018). For the prevention of possible allergic and eczematic reactions on the skin of the feet, as well as the prevention of the development of fungal diseases of the feet, it is necessary to have a sanitary and epidemiological conclusion on the materials used in the shoes. Also, the design of the footwear should ensure, throughout the entire working time, the maintenance of optimal microclimate indicators (temperature, humidity and carbon dioxide content) in the intra-footwear space (Makhotkina, Khristoliubova, 2015).

The safety of footwear mainly depends on the materials used on the parts of the footwear and is laid down at the stage of material selection. In recent years, the question has arisen about the need to create materials that ensure the biological safety of shoes. Microorganisms affect not only the human body, but also the materials used in the manufacture of footwear (Ilkhamova, Maksudova, Mirzayev, Pazilova, 2017). Due to huge material losses, at present, material manufacturers are paying more and more attention to the biological protection of various materials, including textile ones, damaged during their production, storage and operation. One of the directions in the 
biological protection of materials is the creation of fibrous materials with antibacterial and antifungal treatment, as well as products from them for the needs of medicine (Makhotkina, Khristoliubova, Khannanova-Fakhrutdinova, 2016).

The differences between antibacterial, bactericidal and bacteriostatic types of materials should be clearly defined. Antibacterial fabrics prevent the growth of bacteria due to the action of the active substance, which is applied to the fabric during the finishing process. However, it is gradually removed from its surface under the influence of washing (Makhotkina, Sharifullin, 2016). Bactericidal cloths destroy bacteria with the action of a powerful antiseptic that destroys microorganisms. They are mainly used in medicine. Bacteriostatic cloths stop the process of bacterial reproduction and the growth of fungi without killing them. The active substance is more or less resistant to washing, because it is introduced into the fibers and, thus, its effect persists for a long time. These fabrics are able to prevent the unpleasant odor that usually occurs with active perspiration. They are made in different forms: knitwear, woven fabrics, fleece fabrics, etc. Bacteriostatic fabrics were originally developed for sports (underwear and footwear), but now bacteriostatic materials are one of the priority directions in the development of textile materials (Khaliullina, Gadelshina, 2014).

Health-preserving footwear for special purposes should ensure at least the preservation and at the maximum the strengthening of the health of the wearer, i.e., to prevent occupational injuries and to prevent the occurrence of occupational diseases that may arise not only due to the inappropriate protective and ergonomic properties of the footwear, but also due to the unsafeness of the footwear itself for the wearer.

At the same time, the shoes should not lose their health-preserving function during the entire period of wearing, established in the technical regulation TS 019/2011, documents of the Ministry of Health, resolutions of the State Standard of Russia No. 34. Thus, we can conclude that the healthpreserving function of special-purpose footwear will largely depend on the preservation of its ergonomic, protective and safety properties (Figure 1). Satisfaction of this set of properties ensures the preservation of the health of workers who use special-purpose footwear for their work.

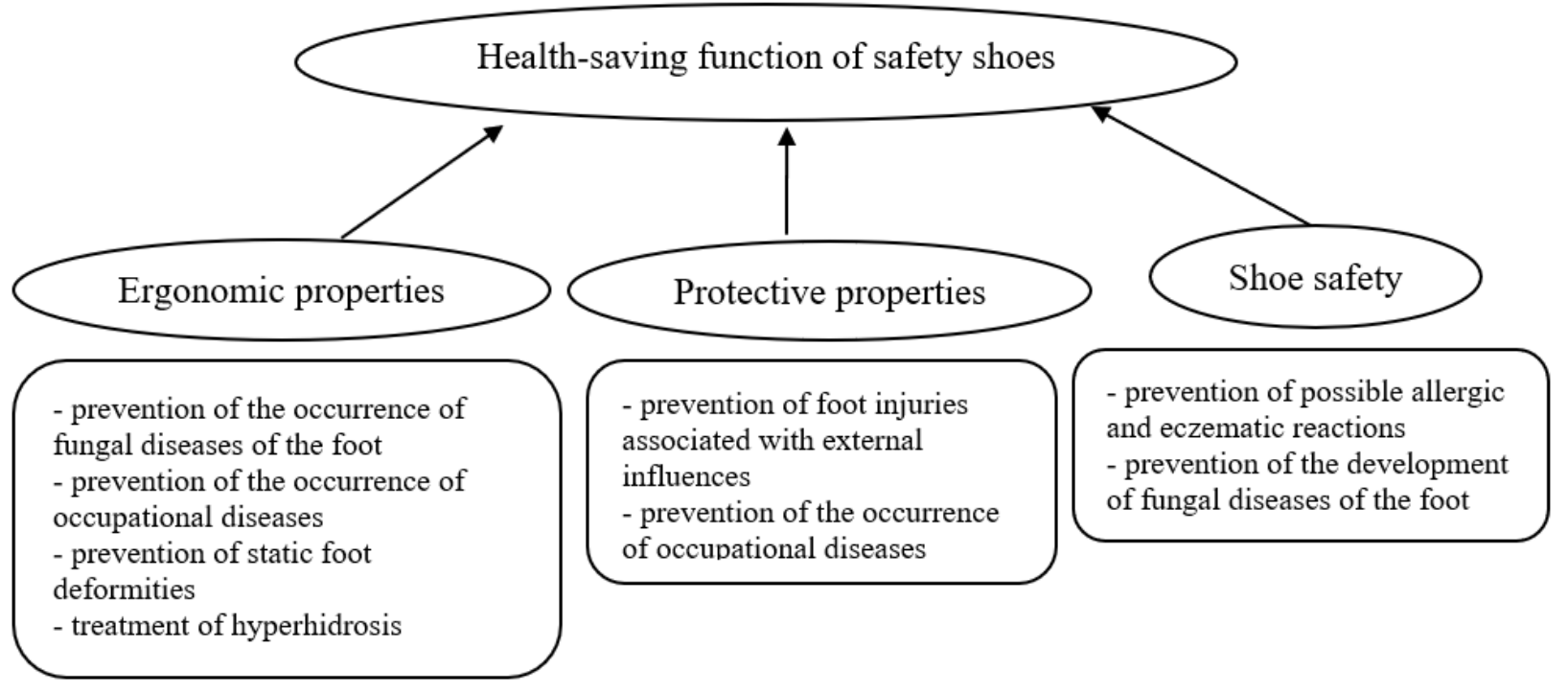

\section{Figure 1. Dependence of the health-preserving function of footwear on its consumer properties}

\section{Results and Discussion}

Modern footwear for special purposes is a sophisticated high-tech product that must have a healthpreserving function. The health-preserving function of safety footwear depends on the following 
consumer properties: protective, ergonomic and safety, and is ensured by the rational selection of a package of materials for the details of the shoe. Ensuring the health-preserving function of the shoe is laid down at the stages of its design, starting with the stages of choosing a design solution and choosing materials for the elements of shoe construction. When choosing materials, it is necessary to take into account hygienic (steam, air permeability, moisture capacity, sorption capacity, volatility), moisture-proof (water permeability, wetness, moisture capacity), heat-shielding (total thermal resistance, thermal conductivity), shockproof (maximum shock load, resistance to through puncture), toxicological properties of materials. For a rational choice of materials and design solutions of footwear, it is necessary to take into account the change in consumer properties during operation and the effect of these changes on the health of wearers for experimental confirmation of the dependence of the health-preserving function of special-purpose footwear on its protective, ergonomic and safety properties.

To determine how the consumer properties of special-purpose shoes change in the process of wearing, and how these changes affect the health of wearers, we conducted a survey of wearers of special shoes with protection against electric shock and electric arc damage from three organizations in Kazan (CHP-2, LLC Ashan-Retail, LLC "AGAVA"), and observation of constructive changes in the shoe during the process of wearing. The professional activity of employees of these organizations is associated with the possible impact of electric current from electrical installations and when working with electrical equipment (electric powder, electric stacker, double-force, reach truck, etc.). They wear special shoes throughout the eight-hour work shift.

A total of 100 people took part in the survey, of which 71 were men and 29 were women. The survey and observation were carried out at different periods of wear: at the beginning, in the middle and at the end of the wear. As a period of wearing, we have chosen the established shoe service life by the technical regulations of CU 019/2011, equal to one year. The service life of a shoe is understood as the period of time during which the manufacturer undertakes to provide the consumer with the opportunity to use the shoe for its intended purpose and is responsible for significant deficiencies that may arise in the shoe. The respondent was asked to evaluate the protective and ergonomic properties (weight, flexibility, hygienic properties) of the special-purpose shoes they wear, which affect the health-preserving function. The safety of footwear was not assessed by the respondents. At the initial stage of socks, it is provided, since materials with a sanitary and epidemiological conclusion are used in the production of special-purpose footwear. However, in the process of wearing, a biological hazard of shoes can arise. To assess it, it is advisable to use research in specialized laboratories studying the migration of microorganisms. The assessment was carried out on a five-point scale, where "1" means a complete inadequacy of the footwear properties to the requirements of the wearer, "2" - non-conformity of the footwear properties to the requirements of the wearer, "3" - partial conformity of the footwear properties to the requirements of the wearer, "4" - the conformity of the footwear properties to the requirements of the wearer, and score "5" - full compliance of the property with the requirements of the carrier meets the score.

Evaluation of protective properties of safety footwear by wearers at different periods of wearing (Figure 2) showed that they change insignificantly over time. The average value of the assessment of the protective properties of the shoe is close to "5", which means: the protective properties are fully consistent with the requirements of the wearer. This is explained by the fact that the indicators of the protective properties of special-purpose footwear are strictly regulated by regulatory documents. 


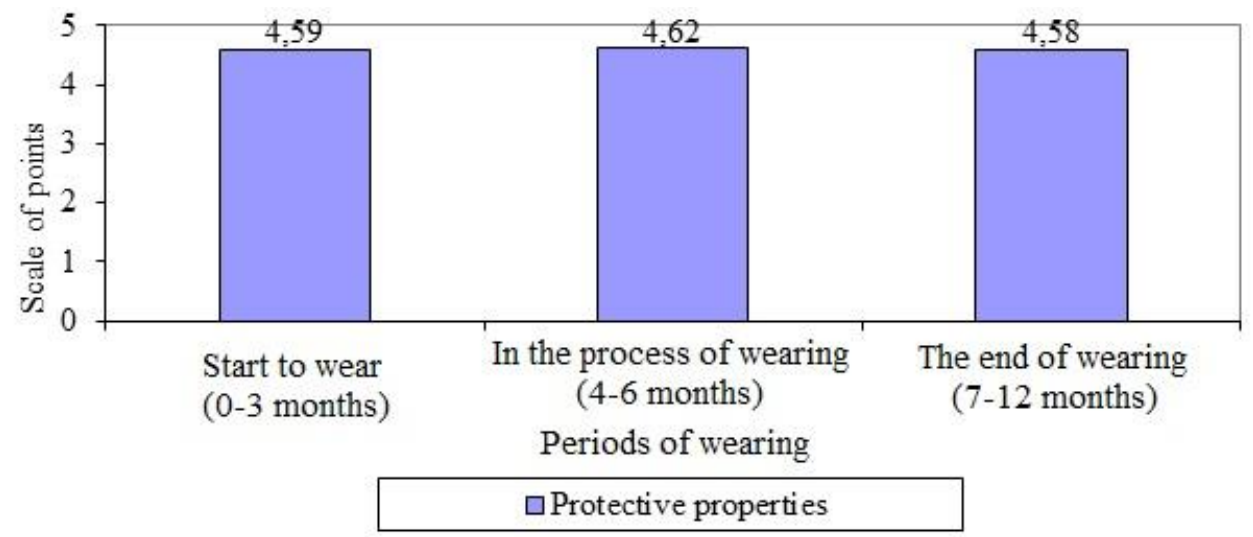

Figure 2. Diagram of the assessment of the protective properties of special-purpose footwear by the wearers at different periods of wearing

Figures 3 and 4 show diagrams of the wearer's assessment of the mass and flexibility of specialpurpose footwear, respectively, at different periods of wearing. At the beginning of wearing, the shoes are heavy, rather stiff, rubbing the foot. In the middle period, they spoke positively about the comfort of wearing shoes: it became more flexible, stopped rubbing on the heel and ankles, and the insole was molded to the running surface of the foot. Based on estimates of close "3" mass and flexibility of shoes from the beginning of wearing, we can conclude that they only partially meet the requirements of the wearers, from the very beginning it does not correspond to the power and speed capabilities of a person, which leads to rapid fatigue and a decrease in the performance of the wearer.

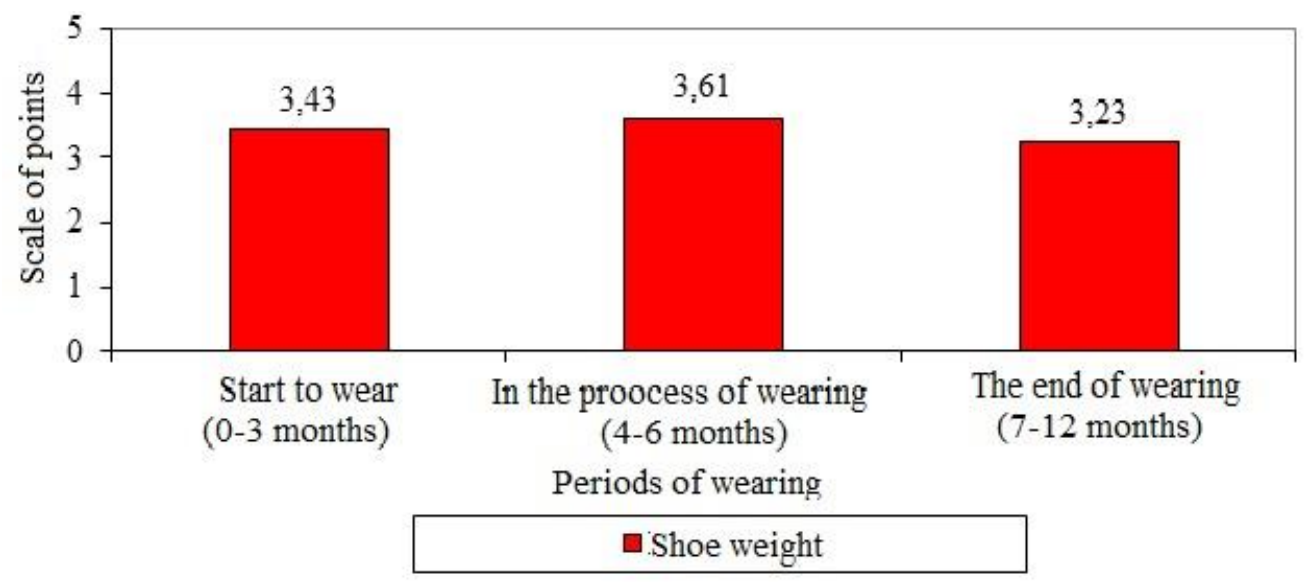

Figure 3. Chart for assessing special-purpose footwear at different wearing periods

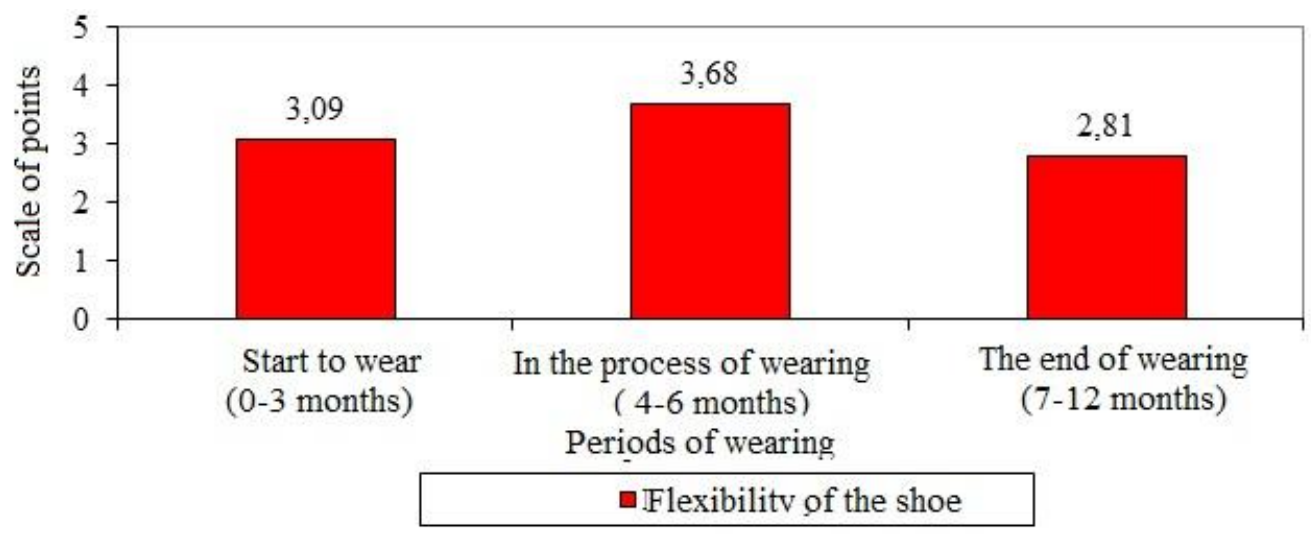




\section{Figure 4. Diagram for assessing the flexibility of special-purpose shoes at different wearing periods}

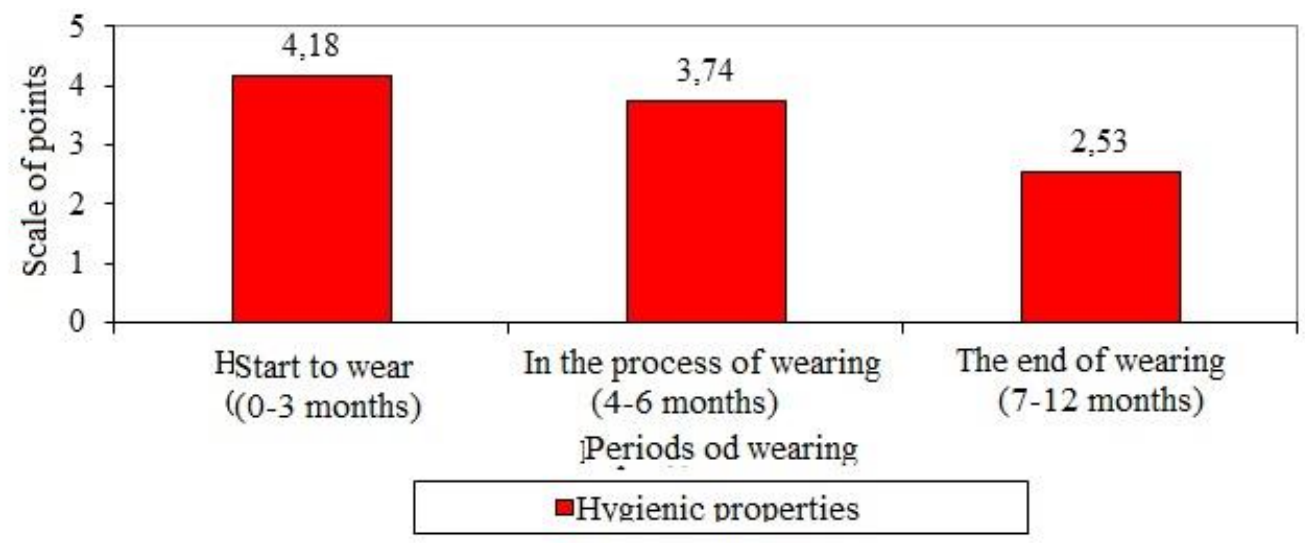

\section{Figure 5. Diagram of the assessment of the hygienic properties of footwear for special purposes in different wearing periods}

Evaluation of the hygienic properties of special-purpose shoes (Figure 5) at the beginning of the wear indicates their compliance with the requirements of the wearers. However, over time, wear ratings change significantly. Towards the end of the wear, the shoes begin to bring discomfort to the wearers due to the deterioration of the in-shoe microclimate. This is mainly due to the clogging of the pores of the materials used for the upper parts, salts of sweat released during the previous period of wear. The deterioration of hygiene properties can lead to a deterioration in the biological safety of shoes due to the development of colonies of microorganisms that cause fungal diseases.

Monitoring the condition of special-purpose shoes during operation showed that the main changes are related to the appearance. The first folds are visible in the toe of the shoe after the first month of wear. At the end of the socks, the appearance of the shoes worsened: through holes in the toe part became visible, in some places the sole was detached, the thread seams were destroyed, $22 \%$ of the studied shoe samples were replaced with new ones.

\section{Conclusion}

Based on the results of the work carried out, it was found that the health-preserving function of special-purpose footwear is a complex function that equally implements both protective and physiological and hygienic functions. This is due to the fact that safety shoes, first of all, must protect the wearer's foot from dangerous industrial injuries, be safe, convenient and comfortable during operation, thereby preserve his health, prevent diseases arising from external exposure, and not be the very source of diseases. Changes in the protective, ergonomic and safety properties, primarily biological, of special-purpose footwear in the process of wearing lead to a change in the health-preserving function.

Thus, when choosing materials and designing the construction of special-purpose footwear, it must be remembered that footwear is a product that is in close contact with a person's foot. It should not have a negative effect on the structure of the foot, cause diseases of the human musculoskeletal system, due to the irrational shape of the shoe, cause eczematic and allergic reactions due to the use of materials that are not harmless to the human body, especially on the inner parts of shoes, fungal diseases due to for unsatisfactory moisture exchange properties of both materials and shoe construction.

Further development of the presented work will be laboratory research, the purpose of which will be to establish the optimal values of the ergonomic properties and safety properties of special-purpose footwear to ensure health-preserving function. This is necessary, since the indicators of these 
properties, in contrast to the protective properties, are not clearly regulated in the normative and technical documentation.

\section{Contribution}

Makhotkina Lilia Yurievna - consideration of theoretical issues on health preservation problems, definition of the research concept, formulation of the main sections of the article

Nikitina Lyudmila Leonidovna - consideration of theoretical issues on health preservation problems, definition of the research concept, formulation of the main sections of the article

Yarullin Rinat Mudarisovich - consideration of theoretical issues on health preservation problems, definition of the research concept, formulation of the main sections of the article.

Tikhonova Natalya Vasilievna, the protective properties of special-purpose footwear are considered.

Garipova Guzel Ilgizarovna - substantiation of the research methodology. Consideration of consumer properties of footwear (ergonomic).

Hannanova-Fakhrutdinova Lilia Rafailevna - substantiation of the research methodology. Consideration of consumer properties of footwear (safety properties).

Each of the authors identified in the article participated in the organization and conduct of the survey of respondents and in the design of the research results.

\section{References}

Akimova, E.V. (2005). Assessment of the quality of footwear based on the results of its examination during the warranty period of socks. Leather and footwear industry, 1, 27-28.

Alexandrov, S.P., Zhukovskaya, T.V. (2014). Amortization of the human body in the phase of full support on the foot. Collection of scientific articles and memoirs "In memory of V.A. Dedicated to Fukin", 36-45.

Alexandrov, S.P., Zhukovskaya, T.V. (2019). Factors of the Fretting Phenomenon Model in the Development of Health-Saving Shoes. Collection of articles of the All-Russian Scientific and Technical Conference "Fundamental and Applied Problems of Creating Materials and Aspects of Textile and Light Industry Technologies", 280-286.

Belgorodsky, V.S. (2001). Development of methods and means for increasing the comfort of shoes: abstract of the dissertation of the candidate of technical sciences. Moscow.

Ilkhamova, M., Maksudova, U., Mirzayev, N., Pazilova, D. (2017). Research of footwear lining materials thermoconductive properties. IOP Conference Series: Materials Science and Engineering. 17, Shaping the Future of Textiles. Cep. "17th World Textile Conference, AUTEX 2017: Shaping the Future of Textiles - Leather and Shoes Industry", 232007.

Ivanov, M.N., Glazer, E.S. (1982). Assessment of shoe comfort. Leather and footwear industry, 2, 23-27.

Kedrov, L.V. (1979). Heat protection properties of footwear. Moscow: Legprombytizdat.

Khaliullina, M.K., Gadelshina, E.A. (2014). The use of various bactericidal and fungicidal additives in polymers in the production of antimicrobial textile materials. Bulletin of Kazan Technological University - Kazan: Publishing house of KNITU.

Kiselev, S.Yu. (2004). Computer-aided design and manufacturing of technological equipment for the production of footwear and prosthetic and orthopedic products: thesis abstract of Doctor of Technical Sciences. Moscow. 
Kiseleva, M.V. (2008). Development of a rational design of medical preventive footwear and footwear of increased comfort: abstract of the dissertation of the candidate of technical sciences. Moscow.

Kostyukhova, Yu.S. (1999). Development of a methodology for the computer-aided design of inline orthopedic footwear devices: on the example of a woman's: abstract of the dissertation of a candidate of technical sciences. Moscow.

Lyubich, M.G. (1969). Shoe properties. Moscow: Light industry.

Magomedov, Sh.Sh. (2007). Commodity research and examination of footwear. Moscow: Dashkov and Co.

Makhotkina, L.Y., Khristoliubova, V.I. (2015). Variation of footwear wear resistance depending on methods of treatment. International Journal of Applied and Fundamental Research, 1, 13.

Makhotkina, L.Y., Khristoliubova, V.I., Khannanova-Fakhrutdinova, L.R. (2016). Design of special purposes products made of nanomodified leather. Mathematics Education.

Makhotkina, L.Y., Sharifullin, S.N. (2016). Design of special purpose products made of nanomodified collagen containing materials with radio frequency discharge. IOP Conference Series: Materials Science and Engineering.

Makhotkina, L.Y., Tikhonova, N.V., Zhukovskaya, T.V., Garipova, G.I., Kovalenko, Y.A., Fatkhullina, L.R., Khristoliubova, V.I. (2020). Effect of non-equilibrium low temperature plasma on genuine leather adhesion properties of special purpose footwear upper to molding compositions with polyurethanes base. Key Engineering Materials, 296-302.

Makhotkina, L.Yu., Nikitina, L.L., Gavrilov, O.E. (2017). Design of light industry products: design of leather products. Moscow: INFRA-M.

Maksimova, I.A. (2003). Creation of designs of low-complexity orthopedic footwear of mass production: dissertation of the candidate of technical sciences. Moscow.

Nikolaeva, T.A. (1999). Development of methods and means for improving the intra-shoe space: abstract of the dissertation of the candidate of technical sciences. St. Petersburg.

Polukhina, O.S. (2004). Regulation of biological properties of medical materials by photochemical treatment of their surface: abstract of the dissertation of the candidate of biological sciences. Moscow.

Reshetneva, T.T., Kalita, A.N. (1978). Increasing the moisture-protective properties of sports shoes. Express information. Shoe industry in the USSR. TsNIITEIlegprom, 5.

Savoskin, E.M. (2016). Development of an automated process for creating orthopedic pads based on contactless measurement of feet, design and manufacture: abstract of the dissertation of the candidate of technical sciences. Kazan.

Serweta, W., Olejniczak, Z., Lasoń-Rydel, M., Matusiak, M. (2018). Analysis of thermal insulation properties of selected material packages for footwear uppers. PrzegladWlokienniczy, 72(8), $39-43$.

Weir, G., Hamill, J., Willwacher, S., Trudeau, M.B., Wyatt, H. (2020). The influence of prolonged running and footwear on lower extremity joint stiffness. Medicine and Science in Sports and Exercise, 52(12), 2608-2614.

Yarullin, R.M., Nikitina, L.L., Makhotkina, L.Yu., Tikhonova, N.V. (2019). Designing healthsaving footwear for special purposes. Materials of the international correspondence scientific-practical conference "Technical regulation: the basic basis for the quality of 
Fundamental and applied problems of materials creation and phases of technologies for textile industry

materials, products and services." Institute of the Service Sector and Entrepreneurship (branch) of the Federal State Budgetary Educational Institution of Higher Professional Education "Don State Technical University".

Zayonchkovsky, A.D., Krasnov, B.Ya. (1977). Some new problems in the field of designing antistatic footwear from polymeric materials. Moscow: VZITLP.

Zurabyan, K.M., Krasnov, B.Ya., Bernstein, M.M. (1988). Materials science of leather goods. Moscow: Legprombytizdat. 